\title{
Optimization of a Route Network in Dakar Airspace: Surface Navigation
}

\author{
Mint Elhassen Emani1 ${ }^{*}$, Amadou Coulibaly¹, Salimata G. Diagne ${ }^{1}$, Ahmedou Ould Haouba ${ }^{2}$, \\ Alain Ngoma Mby3 \\ ${ }^{1}$ Cheikh Anta Diop University, Dakar, Senegal \\ ${ }^{2}$ University of Nouakchott AL Aasriya, Nouakchott, Mauritanie \\ ${ }^{3}$ Agency for Aerial Navigation Safety in Africa and Madagascar, Dakar, Senegal \\ Email: *emanihassen@yahoo.com
}

How to cite this paper: Emani, M.E., Coulibaly, A., Diagne, S.G., Haouba, A.O. and Mby, A.N. (2022) Optimization of a Route Network in Dakar Airspace: Surface Navigation. American Journal of Operations Research, 12, 64-81

https://doi.org/10.4236/ajor.2022.122004

Received: January 14, 2022

Accepted: March 1, 2022

Published: March 4, 2022

Copyright (C) 2022 by author(s) and Scientific Research Publishing Inc. This work is licensed under the Creative Commons Attribution International License (CC BY 4.0)

http://creativecommons.org/licenses/by/4.0/

\begin{abstract}
In this paper, the map of a network of air routes was updated by removing the non-optimal routes and replacing them with the best ones. An integer linear programming model was developed. The aim was to find optimal routes in superspace based on performance-based navigation. The optimal routes were found from a DIJKSTRA algorithm that calculates the shortest path in a graph. Simulations with python language on real traffic areas showed the improvements brought by surface navigation. In this work, the conceptual phase and the upper airspace were studied.
\end{abstract}

\section{Keywords}

Airspace, Linear Optimization, Graph Theory, Dijkstra Algorithm, Performance-Based Navigation, Conventional Navigation

\section{Introduction}

The increase in air traffic poses a real problem as control agencies have to simultaneously manage an ever-increasing number of aircrafts in already congested airspace and maintain a high level of safety. This continuous traffic growth pushes the navigation system (Conventional Navigation) to its limits and the need for alternatives with greater capacity becomes more and more urgent [1]. However, navigation systems have had to undergo constant technological development. One of these developments is Area Navigation (RNAV). A new navigation method called RNAV (Area Navigation) defined by [2] at the ICAO (International Civil Aviation Organization) 4th edition 2013 conference, tries to bring new solutions. 


\section{Vocabulary}

- Conventional Route: A conventional air route is a succession of segments in the horizontal plane, the ends of which are waypoints located above groundbased radio navigation equipment (e.g., VOR2 beacons).

- Surface Navigation: A method of navigation which allows flight on any desired trajectory within the coverage of ground or space-based navigation aids, or within the capability of an autonomous aid, or by a combination of these means.

- Area Navigation Route. ATS route established for use by aircraft that can use surface navigation.

- GNSS (global navigation satellite system) is the generic name for satellite navigation systems providing global geo-positioning coverage (Duquenne et al., 2005). The objective of this system is to give the geolocation of a mobile device as well as its speed at any location on the globe and in a global reference frame.

\subsection{State of the Art}

Let us first place our approach in context, before presenting the concrete steps. A certain amount of work has already been done on airspace sectorisation (e.g., [3] [4]), you consider the Dynamic Airspace Sectorization Problem (DASP) where airspace is partitioned into a number of sectors. The objective of DASP cited in [4], is to balance the controllers' workload among the sectors and to simultaneously minimize the coordination workload between adjacent sectors. The allocation of flight levels in cruise mode (the definition of separate direct routes) [5]: the basic idea is to consider direct routes only and vertically separate intersecting ones by allocating distinct flight levels, thus leading to a graph coloring problem. The construction of air route networks is cited in [6]. The work objective is to balance the traffic among the network's routes and sectors and modifications of the network may also be decided, in order to increase the overall capacity. In this context, airlines operators are free to choose a flight path and a requested flight level for each of their flights, on a day-to-day basis. A consequence is that many flights request the same flight levels and the most direct routes, thus increasing airspace congestion. This system is now reaching its limits.

The creation of a network of air routes is treated by Thomas RIVIERE cited in [7] the work is centred on the study of a new concept called Sector-Less, imagined by a team of the Eurocontrol agency. In order to respond to the problems posed by the increase in air traffic, this new concept radically redefines the way in which air traffic management and control are carried out.

Then, the problem of optimizing the air route network was the subject of Vincent Letrouit's work, cited in [8]. This addresses the feasibility of a new air route network that could integrate on the one hand straight air routes between airports and on the other hand the possibility for aircraft to change level once or several times between origin and destination at predefined points, in order to avoid potential conflict points. The concept is considered impractical, but does not con- 
sider a possible navigation specification for the routes. Furthermore, the mathematical models that exist in the literature have not addressed the various problems related to air transport and performance-based navigation.

The Location of Air Routes Is a very Important Phase in Air Navigation

The current air network is made up of a set of segments which intersect at particular points defined by beacons emitting signals from the ground.

\section{Our Contribution}

The work presented here takes place in this context and aims to make a better location of air routes adapted to this new navigation method.

First, we will present the Dakar airspace and the current situation of roads and then we will show the problem. In the second part of this paper, we develop an integer linear programming model and solution for this application using the shortest path algorithm, the Dijkstra algorithm. The simulation and interpretation of the results are presented in Part 3. Part 4 concludes the work.

\subsection{Presentation of the Dakar Airspace}

Terrestrial Dakar Airspace covers 6 countries, namely Senegal, Mauritania, Mali, Gambia, Guinea Bissau and Cote d'Ivoire, covering about 8 million square kilometres. This space is composed of a set of air routes [9]. These routes are represented in the radio navigation map by a succession of segments in the horizontal plane, the ends of which are located above the radio navigation medium (VOR, DME, NDB, VOR-DME)

\section{Navigation Technique}

Navigation technique Traditional aviation navigation techniques have been developed using ground-based navigation aids. There are various types of navigation facilities, including:

- A Non-Directional Beacon (NDB) is a radio transmitter at a known location that an aircraft can track to/from;

- Omnidirectional VHF range (VOR) that provides more accurate directional navigation information;

- Distance Measuring Equipment (DME) that provides information on the distance to/from the facility.

The set of airspaces managed by ASECNA (Agency for Aerial Navigation Safety in Africa and Madagascar), among which there is the Dakar land area (Fir Dakar Terrestre), see Figure 1.

Lateral Boundaries of the Different Flight Information Regions of Dakar Land

A volume whose "horizontal" outline generally follows the administrative borders of these countries: The FIR (as currently defined on the WBAI) are Algiers DAAA (Algeria), Abidjan DIII (Ivory Coast), Casablanca GMMM (Morocco), Canarias GCCC (Spain), Niamey DRRR (Niger + Burkina Faso), Roberts GLRB (Liberia + Sierra Leone + Guinea), Sal Océanique GVSC (Cape Verde) and the Dakar Océanique FIR GOOO. Some FIRs are attached to active VNAI divisions, others are not (DRRR, GLRB, DIII). 


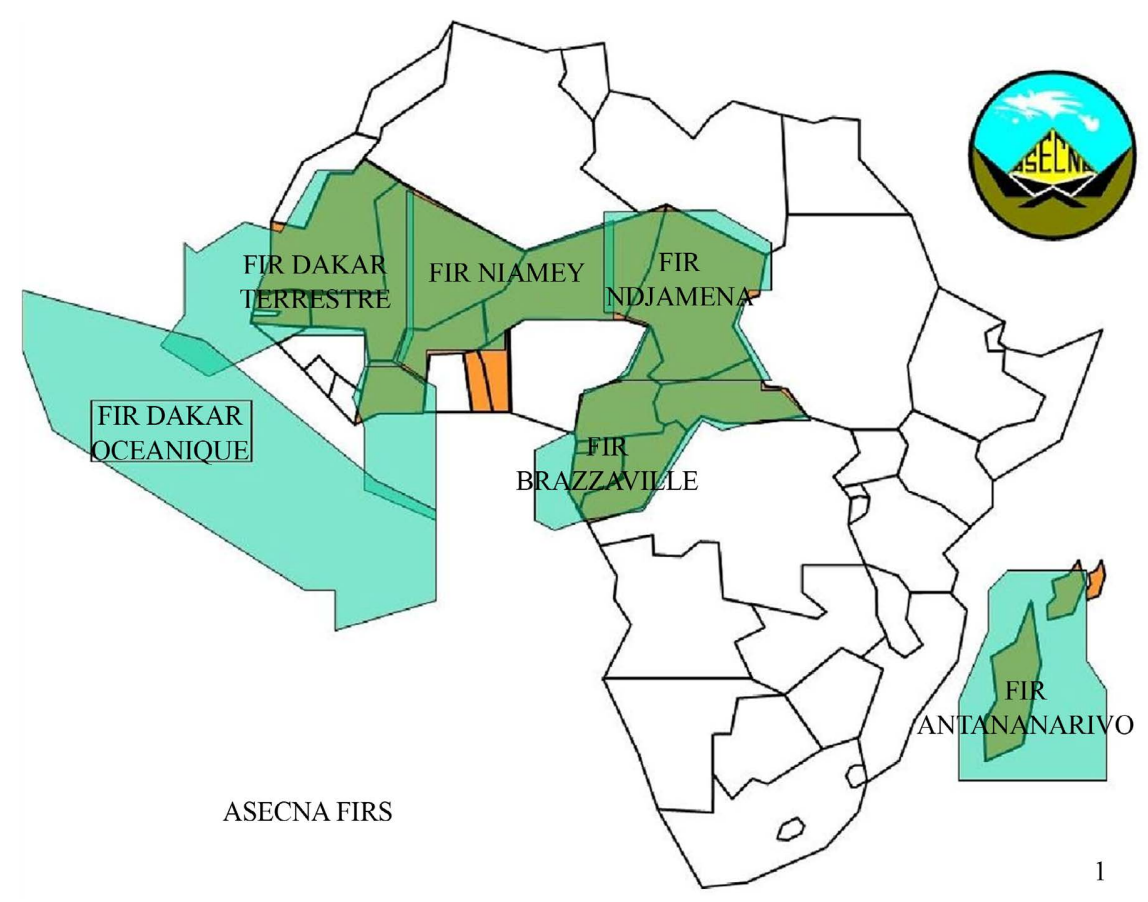

Figure 1. ASECNA FIRs.

- IVAO: International Virtual Aviation Organization;

- FIR: Flight Information Region;

- DAAA: CODE ICAO (International Civil Aviation Organization) for FIR (Flight Information Region) Alger;

- GCCC: CODE ICAO for FIR (Flight Information Region) Canarias;

- GVSC: CODE ICAO for FIR (Flight Information Region) CAP Verde;

- GOOO: BCODE ICAO for FIR (Flight Information Region) Dakar Oceanique.

\subsection{Presentation of the Problem}

1) ASECNA proposes to work on a part of the Dakar land airspace with conventional routes. The current air network is composed of a set of segments that intersect at particular points defined by beacons emitting signals from the $\mathrm{g}$ round.

The land-based Fir Dakar is made up of 26 conventional roads with a high traffic density.

2) The work presented here takes place in this context and aims to make a better location of air routes suitable for this new navigation method.

Note: In this work, we are interested in conventional routes in the upper airspace.

The objective of our study is to transform conventional routes into RNAV routes.

The Value of Working on the Operational Phase

1) To make direct routes;

2) Reduce the number of crossing points between roads; 
3) Make the roads more and more parallel;

4) Reduce controller work.

\subsubsection{The General Problem}

The large terrestrial Dakar area consists of several sub-areas and several cities to be connected. For two given cities, one of which is the initial city and the other the destination city, we look for all possible routes connecting these two cities and we look for the route that corresponds to the shortest path.

General probability is defined as the union of optimization subproblems each of which is independent of the other.

\subsubsection{Sub-Problem}

\section{First Problem}

For a problem $P_{l}$ from for example the case of the couple (Nouadhibou, Abidjan) $I=1, P_{l}$ is $P_{1}$ and the first subgraph page (8) corresponds to $P_{1} P_{l}: \sum d_{i, j} X_{i, j}^{l}$

Hypothesis: Our problem is to find the shortest path with an adiditional constraint between two given cities: city of origin and city of destination on the following assumption.

Dakar airspace is capable of applying PBN (Performance Based Navigation) (see Figure 2 [10]).

\section{Physical Description}

- Our objective is to determine the optimal routes for the Dakar land area, i.e., those that minimize the distances between the different origins and the respectively associated destinations.

\section{Conventional Route}

A conventional air route is a succession of segments in the horizontal plane, the ends of which are waypoints located above ground-based radio navigation equipment [11] (e.g., VOR2 beacons), see Figure 3.

A route is defined by:

- Its origin;

- Its points of passage;

- Its destination.

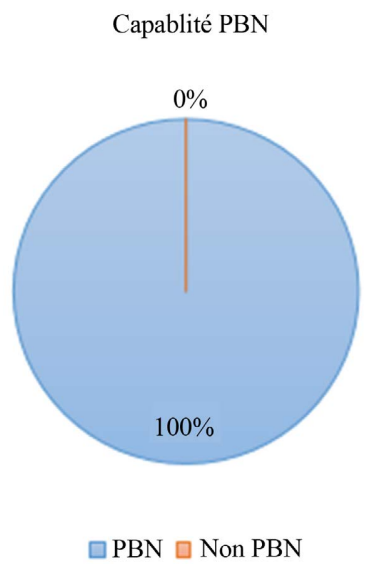

Figure 2. PBN capability in Dakar airspace terrestre. 


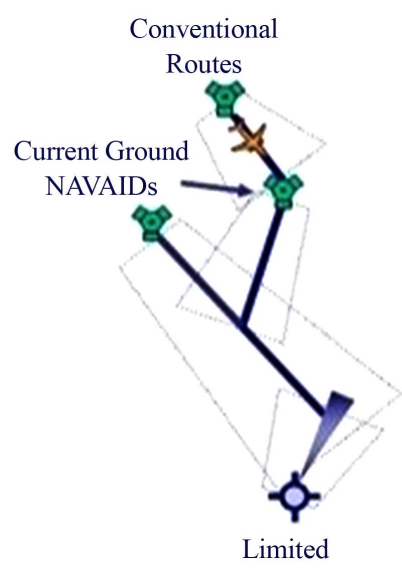

Figure 3. Conventional routes.

The Dakar terrestrial zone is a network of roads mapped by a graph. This graph is an undirected connected graph whose vertices represent cities and geographical points in space and whose edges represent segments connecting cities or geographical points.

Radio-navigation map: includes all air routes in the upper airspace managed by ASECNA (Agency for Aerial Navigation Safety in Africa and Madagascar), see Figure 4 and Figure 5.

\section{Mathematical Model}

NB each zone is defined by as a set of edges.

All input data for our model, Table 1.

\section{Decision Variable}

We have a decision variable that is defined as follows:

$$
X_{i, j}^{l}= \begin{cases}1 & \text { if chooses edge }(i, j) \text { in the determination of the route } l \\ 0 & \text { else }\end{cases}
$$

\subsection{Mathematical Formulation}

We define the General Problem P: The union of all sub-problems $P_{l}$ with $P_{l}$ avec:

$$
\begin{gathered}
\bigcup_{l \in L} P_{l} \\
: \min \sum_{(i, j) \in A^{l}} d_{i, j} X_{i, j}^{l} \\
\sum_{j \in S^{+}(O)} X_{O, j}^{l}-\sum_{j \in S^{-}(O)} X_{j, O}^{l}=1 \quad \forall l \in L \\
\sum_{i \in S^{-}(d)} X_{i, d}^{l}-\sum_{i \in S^{+}(d)} X_{i, d}^{l}=1 \quad \forall l \in L \\
\sum_{j \in S^{-}(i)} X_{j, i}^{l}=\sum_{j \in S^{+}(i)} X_{i, j}^{l} \quad \forall l \in L, \quad \forall i \in S-\left\{O_{l}, d_{l}\right\} \\
\sum_{(i, j) \in B^{d}} Z_{k}^{l} X_{i, j}^{l}=0 \quad \forall k \in M \\
X_{i, j}^{l} \in\{0,1\}
\end{gathered}
$$




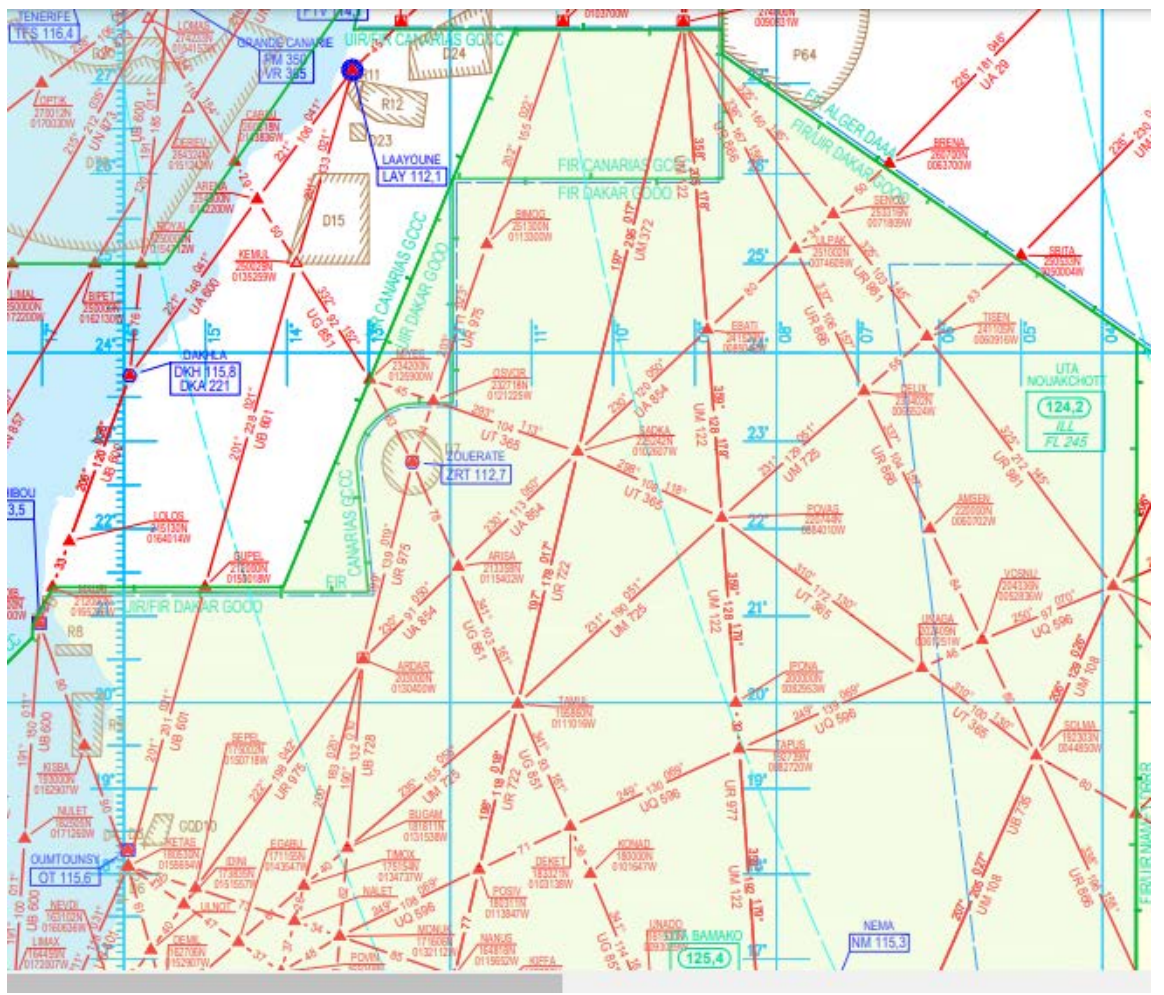

Figure 4. Radio navigation-higher space map 2018.

Table 1. Set and parameters.

\begin{tabular}{cl}
\hline Ratings & \\
\hline$N$ & Set of vertices \\
$S$ & All neighborhoods \\
$A^{l}$ & Set of edges of the road $l$ \\
$O_{l}$ & Origin of the road $l$ \\
$d_{l}$ & Destination of the road $l$ \\
$d_{i, j}$ & Represents the distance between two consecutive vertices $i$ and $j$ of a graph \\
$D_{l}$ & Distance matrix \\
$S^{-}(i)$ & Incoming neighborhood of vertex $i$ \\
$S^{+}(i)$ & Neighborhood exiting the summit $i$ \\
$z_{k}^{l}$ & Area k to be overflown in the determination of the route $l$ \\
$B^{d}$ & All the edges that pass through a danger zone \\
$Z$ & Dakar land zone \\
$L$ & All conventional roads in the area \\
$M$ & All areas in space \\
$l$ & Road $l$
\end{tabular}




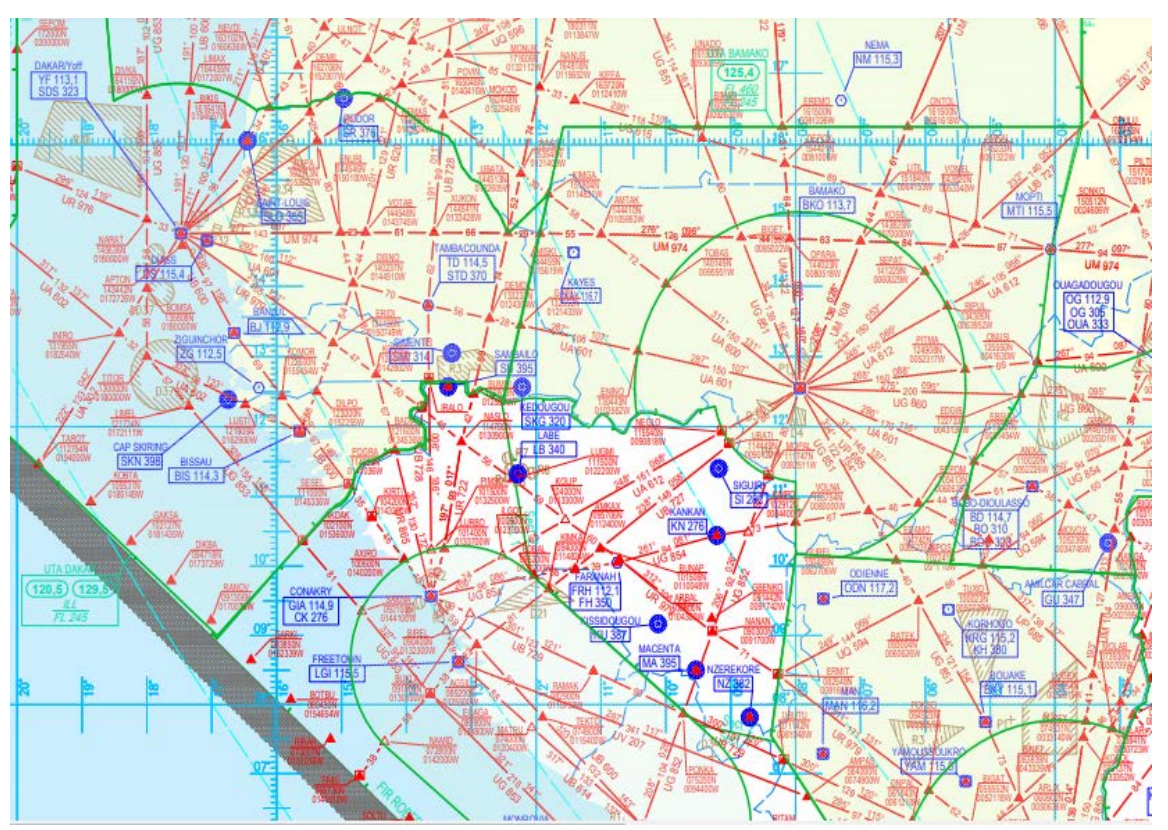

Figure 5. Radio navigation-higher space map 2018.

\subsection{Objective Function}

The objective function to be minimized is the sum of the total distances travelled between the different origins and the respectively associated destinations.

\subsection{Constraints}

1) Constraints 1: Show that at the origin of a road $l$ there is no entry edge.

2) Constraints 2: On arrival at the destination of a road $I$ there is no exit edge.

3) Constraints 3: For any vertex other than $O_{l}$ and $d_{l}$, the number of incoming paths chosen must be equal to the number of outgoing paths(flow conservation).

4) Constraints 4: Show that an air route cannot be created for hazardous areas.

5) Constraint 5: The integrity constraint.

\section{Resolution by Dijsktra}

1) Definition:

The Dijkstra algorithm (pronounced [dj.kstra]) is used to solve the shortest path problem. It allows, for example, determining a shortest route from one city to another knowing the road network of a region [12] [13].

2) Arthmetic Resolution:

- Declare the initial node;

- Add the child nodes and their values;

- Find the shortest path and resume.

3) The dijkstra algorithm allows to efficiently solving shortest path problems in a road network:

$\mathrm{Nb}$ : each problem is represented graphically by an undirected graph. 


\section{Simulation}

Our work was solved by the Dijkstra algorithm, which is programmed by an advanced programming language PYTHON with real traffic data of the Dakar land area taken from a file of the technical department of ASECNA (Agency for Aerial Navigation Safety in Africa and Madagascar) [14].

Roads and road sections consist of a set of cities and fictitious points connected to each other in airspace, see Table 2.

- Figure 6 shows the determination of the UB600 route.

Graph describes cities and geographical points in space and the distances between them, see Figure 6.

- This graph represents the set of routes of which one is optimal.

- Red road is the best.

$\mathrm{Nb}$

The distance matrix associated with Figure 6:

Table 2. Air traffic data for Dakar land area.

\begin{tabular}{|c|c|}
\hline Name & Conventional Roads and Portion of Roads \\
\hline UA302 & ABROLHOS/DAKAR \\
\hline UA600 & NOUADHIBOU/NOUAKCHOTT/BAMAKO/NIAMEY \\
\hline UA602 & MOGSA/TITOR/BISSAU \\
\hline UA612 & CONAKRY/BAMAKO/MPOTI \\
\hline UA854 & BENABAS/BRENA/ATAR \\
\hline UA601 & DAKAR/BAMAKO/EBSUD \\
\hline UB600 & $\begin{array}{l}\text { NOUADHIBOU/DAKAR/BANJUL/BISSAU/MONROVIA/ABIDJAN/ } \\
\text { ACCRA/LIBREVILLE }\end{array}$ \\
\hline UB601 & DAKAR/NOUAKCHOTT/ELAAYOUN \\
\hline UB727 & FREETOWN/BAMAKO/OPULU \\
\hline UB728 & ATAR/IRALO/TAMBACOUNDA/CONAKRY \\
\hline UB729 & CONAKRY/UBUTU/ABIDJAN \\
\hline UG615 & MOPTI/KIFFA/NOUAKCHOTT \\
\hline UG851 & MIYEC/ZOUERATE/BAMAKO/BOUAKE/ABIDJAN \\
\hline UG853 & LASPLAMAS/TRAVES NDB/ ABM DAKAR/ABM MONROVIA/LUNDA \\
\hline UG860 & BAMAKO/EDGIB/OUAGDOUGOU \\
\hline UR620 & ATAR/DISNO/BISSAU \\
\hline UR722 & BULIS/BUMBI/CONAKRY \\
\hline UR865 & NOUAKCHOTT/PORGA/CONAKRY \\
\hline UR975 & ECHED/ZOUERATE/ATAR/SAINT-LOUIS/DAKAR \\
\hline UR979 & DAKAR/ABIDJAN \\
\hline UR976 & DAKAR/SAL (“ITINERAIRE”) \\
\hline
\end{tabular}


Graphe 1

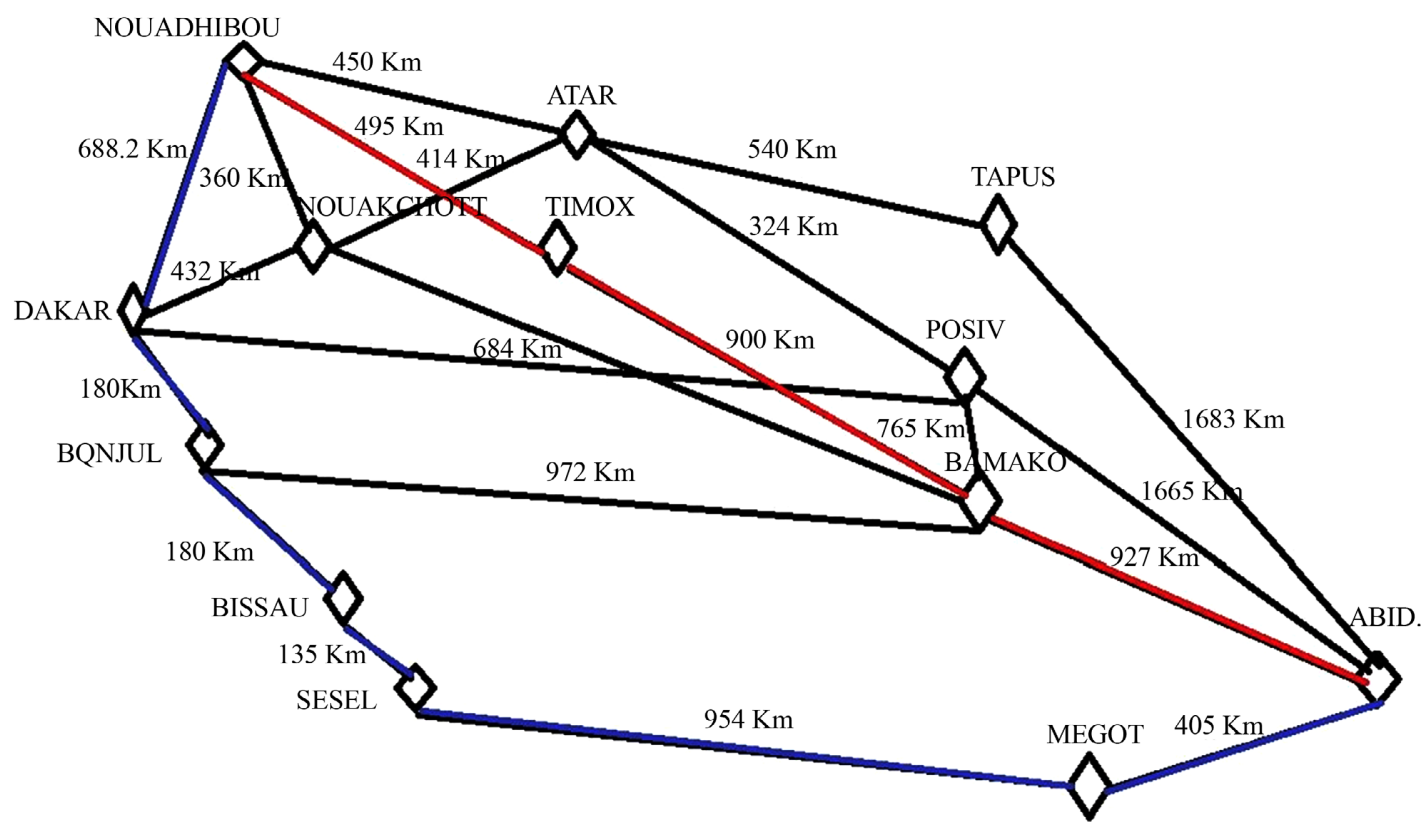

Figure 6. The determination of the UB600 route.

$$
\begin{gathered}
D_{l}=d_{i, j}^{l}: \\
d_{i, j}^{l}= \begin{cases}\infty & \text { if }(i, j) \notin A \\
0 & \text { if } i=j \\
c_{i, j} & \text { else }\end{cases}
\end{gathered}
$$

The matrix representation of sub-problem (Nouadhibou-Abidjan) groups the cities, geographical points and distances between them, see Table 3.

\section{Results}

\subsection{Application of DIJKSTRA}

Dijkstra solving and simulation with an advanced programming language (Phyton) of the models are presented graphically in the annex. The results are presented in Table 4.

Dijkstra's application with the Python programming language stimulation gives the most direct routes, Figure 7 and Figure 8.

\subsection{Interpretation of Results}

After solving the few problems we notice that all the routes that are represented in the radio navigation map in direct lines are optimal in terms of distance, with examples in the annex. The new routes are shown in Table 4.

Route UA302 is the projection of the new route UR975, so the two routes become one route, noted UR975 and the road UG851 and UB600 CONCOURS IN BAMAKO: therefore the portion between BAMAKO/ABIDJAN takes the two notations.

UB600 et UG851 see Table 2. 
M. E. Emani et al.

Table 3. Distance matrix associated with Figure 6.

\begin{tabular}{|c|c|c|c|c|c|c|c|c|c|c|c|c|c|}
\hline & ND & $\mathrm{AT}$ & $\mathrm{TM}$ & $\mathrm{Nk}$ & $\mathrm{DK}$ & $\mathrm{BN}$ & BI & $\mathrm{SE}$ & MG & $\mathrm{PO}$ & $\mathrm{TA}$ & $\mathrm{BM}$ & $\mathrm{AB}$ \\
\hline ND & 0 & $\begin{array}{l}450 \\
\text { KM }\end{array}$ & $\begin{array}{l}360 \\
\text { KM }\end{array}$ & $\begin{array}{c}688.2 \\
\mathrm{KM}\end{array}$ & $\infty$ & $\infty$ & $\infty$ & $\infty$ & $\infty$ & $\infty$ & $\infty$ & $\infty$ & $\infty$ \\
\hline $\mathrm{AT}$ & $\begin{array}{l}450 \\
\mathrm{KM}\end{array}$ & 0 & $\infty$ & $\begin{array}{l}414 \\
\text { KM }\end{array}$ & $\infty$ & $\infty$ & $\infty$ & $\infty$ & $\begin{array}{l}324 \\
\text { KM }\end{array}$ & $\begin{array}{l}540 \\
\mathrm{KM}\end{array}$ & $\infty$ & $\infty$ & $\infty$ \\
\hline TM & $\begin{array}{l}450 \\
\mathrm{KM}\end{array}$ & $\infty$ & 0 & $\infty$ & $\infty$ & $\infty$ & $\infty$ & $\infty$ & $\infty$ & $\infty$ & $\infty$ & $\begin{array}{l}900 \\
\text { KM }\end{array}$ & $\infty$ \\
\hline NK & $\begin{array}{l}360 \\
\mathrm{KM}\end{array}$ & $\begin{array}{l}414 \\
\text { KM }\end{array}$ & $\infty$ & 0 & $\begin{array}{l}432 \\
\text { KM }\end{array}$ & $\infty$ & $\infty$ & $\infty$ & $\infty$ & $\infty$ & $\infty$ & $\infty$ & $\infty$ \\
\hline $\mathrm{DK}$ & $\begin{array}{c}688.2 \\
\mathrm{KM}\end{array}$ & $\infty$ & $\infty$ & $\begin{array}{l}432 \\
\mathrm{KM}\end{array}$ & 0 & $\begin{array}{l}180 \\
\mathrm{KM}\end{array}$ & $\infty$ & $\infty$ & $\infty$ & $\infty$ & $\infty$ & $\infty$ & $\infty$ \\
\hline $\mathrm{BN}$ & $\infty$ & $\infty$ & $\infty$ & $\infty$ & $\begin{array}{l}180 \\
\text { KM }\end{array}$ & 0 & 180 & $\infty$ & $\infty$ & $\infty$ & $\infty$ & $\begin{array}{l}972 \\
\text { KM }\end{array}$ & $\infty$ \\
\hline BI & $\infty$ & $\infty$ & $\infty$ & $\infty$ & $\infty$ & $\begin{array}{l}180 \\
\mathrm{KM}\end{array}$ & 0 & $\begin{array}{l}135 \\
\mathrm{KM}\end{array}$ & $\infty$ & $\infty$ & $\infty$ & $\infty$ & $\infty$ \\
\hline SE & $\infty$ & $\infty$ & $\infty$ & $\infty$ & $\infty$ & $\infty$ & $\begin{array}{l}135 \\
\text { KM }\end{array}$ & 0 & $\begin{array}{l}954 \\
\text { KM }\end{array}$ & $\infty$ & $\infty$ & $\infty$ & $\infty$ \\
\hline MG & $\infty$ & $\begin{array}{l}324 \\
\text { KM }\end{array}$ & $\infty$ & $\infty$ & $\begin{array}{l}684 \\
\text { KM }\end{array}$ & $\infty$ & $\infty$ & $\infty$ & $\infty$ & 0 & $\infty$ & $\begin{array}{l}765 \\
\mathrm{KM}\end{array}$ & $\begin{array}{l}1665 \\
\text { KM }\end{array}$ \\
\hline $\mathrm{PO}$ & $\infty$ & $\begin{array}{l}540 \\
\text { KM }\end{array}$ & $\infty$ & $\infty$ & $\infty$ & $\infty$ & $\infty$ & $\infty$ & $\infty$ & $\infty$ & 0 & $\infty$ & $\begin{array}{c}1683 \\
\text { KM }\end{array}$ \\
\hline TA & $\infty$ & $\infty$ & $\begin{array}{l}900 \\
\text { KM }\end{array}$ & $\infty$ & $\infty$ & $\begin{array}{l}972 \\
\mathrm{KM}\end{array}$ & $\infty$ & $\infty$ & $\infty$ & $\begin{array}{l}765 \\
\mathrm{KM}\end{array}$ & $\infty$ & 0 & $\begin{array}{l}927 \\
\text { KM }\end{array}$ \\
\hline $\mathrm{BM}$ & $\infty$ & $\infty$ & $\infty$ & $\infty$ & $\infty$ & $\infty$ & $\infty$ & $\begin{array}{l}954 \\
\text { KM }\end{array}$ & 0 & $\infty$ & $\infty$ & $\infty$ & $\begin{array}{l}405 \\
\text { KM }\end{array}$ \\
\hline $\mathrm{AB}$ & $\infty$ & $\infty$ & $\infty$ & $\infty$ & $\infty$ & $\infty$ & $\infty$ & $\infty$ & $\begin{array}{l}405 \\
\text { KM }\end{array}$ & $\begin{array}{c}1665 \\
\mathrm{KM}\end{array}$ & $\begin{array}{c}1683 \\
\mathrm{KM}\end{array}$ & $\begin{array}{l}972 \\
\text { KM }\end{array}$ & 0 \\
\hline
\end{tabular}

Table 4. Optimal roads.

\begin{tabular}{ll}
\hline Ratings & New Routes \\
\hline UB600 & NOUADHIBOU/TIMOX/BAMAKO/ABIDJAN \\
UB601 & LAAYOUNE/DAKAR \\
UR975 & ECHED/DAKAR \\
UG851 & MIYEC/ZOUERATE/BAMAKO/ABIDJAN \\
UG853 & AMDIB/PODOR/GATIL/RASAD \\
UA600 & NOUADHIBOU/FORONITERE FIR/NIAMEY \\
UR865 & NOUAKCHOTT/CONAKRY \\
UG615 & NOUAKCHOTT/KIFFA/MOPTI \\
UR620 & ATAR/BISSAU \\
UA602 & MOGSA/ZIGUINCHOR/BISSAU \\
UA302 & ABROLHOS/DAKAR \\
UB728 & ATAR/IRALO \\
UB729 & CONAKRY/ABIDJAN \\
\hline
\end{tabular}




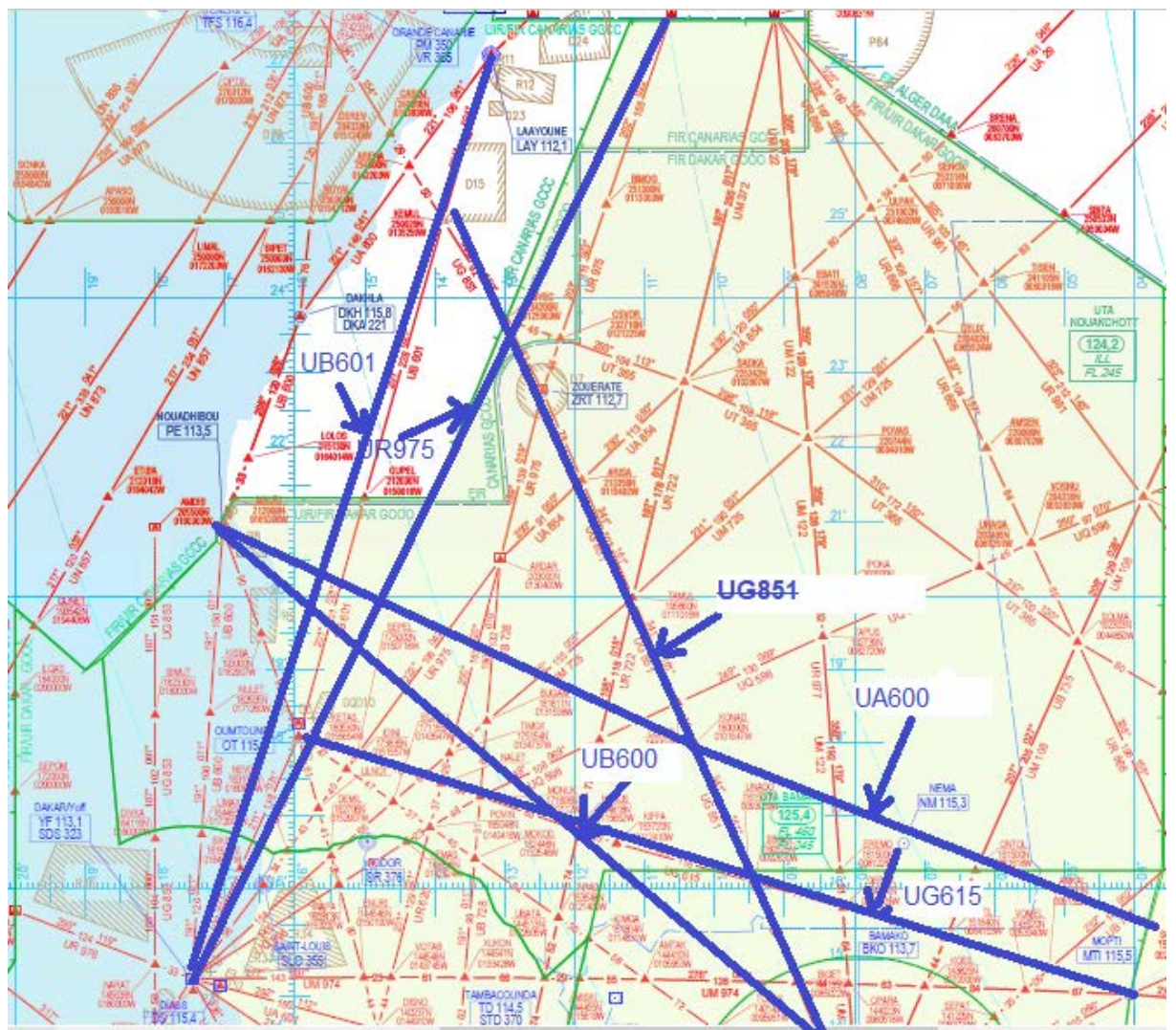

Figure 7. Best solution found by Dijkstra algorithm.

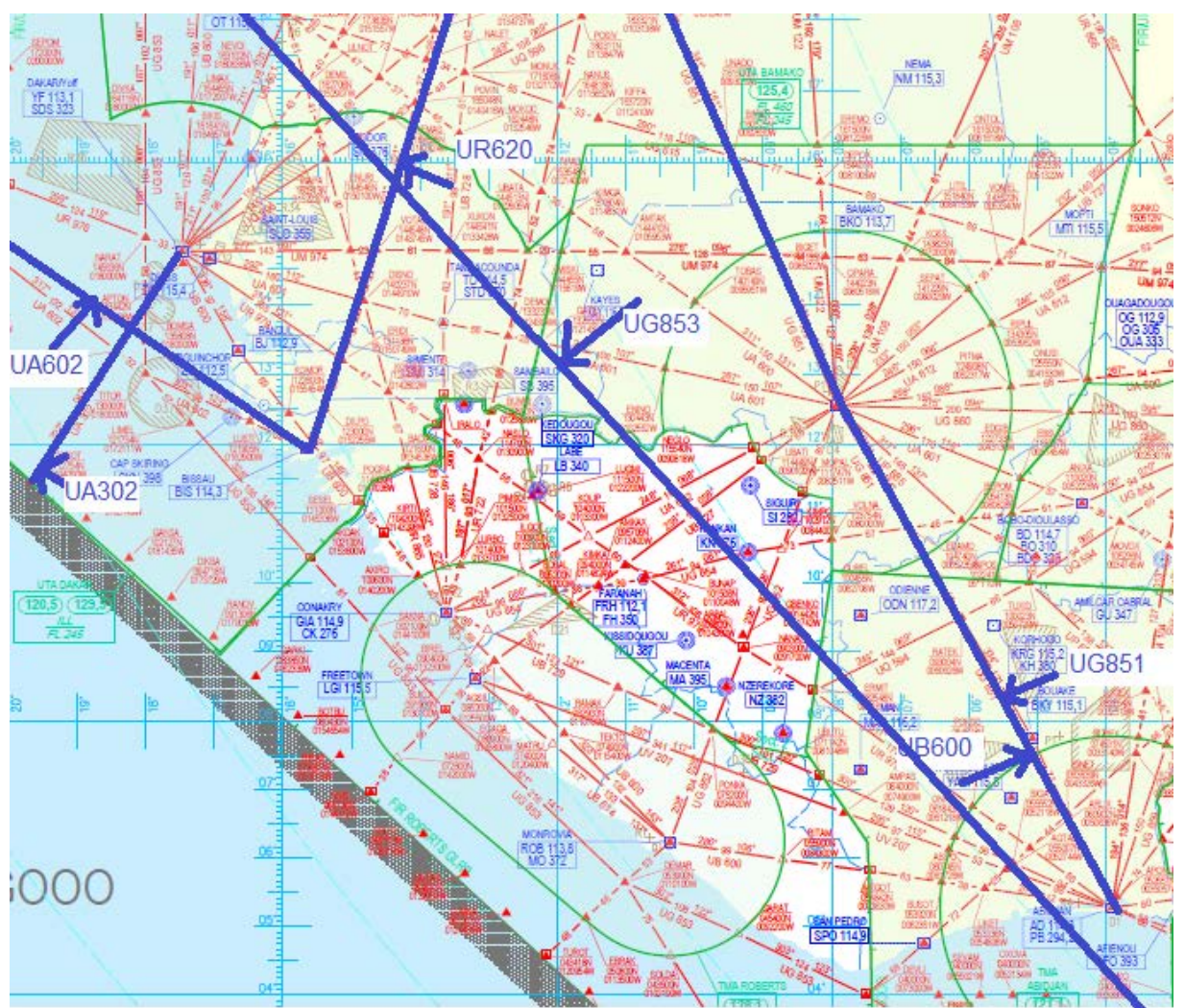

Figure 8. Best solution found by Dijkstra algorithm. 


\section{Conclusions and Prospects}

\subsection{Conclusions}

The objective of our work was to optimize a network of air routes in the Dakar terrestrial space. To achieve this goal, we transform it into PBN space.

The location of the routes is based on the surface navigation method. This method allows an aircraft to use any trajectories within a network of points. Aircrafts flying over the airspace are equipped. We have based ourselves on the RNAV routes, the volume of which is specified by the aircraft's onboard systems.

The advantage is that the graph is no longer in the form of a spider web. Then there will be a gain for all that traffic that will use.

\subsection{Prospects}

Maximizing the capacity of Dakar airspace, this means being able to put more aircraft in the airspace, taking into account:

- Specification of optimal routes in the Dakar terrestrial zone.

- Horizontal separation minima which is applicable in continental regions.

\section{Conflicts of Interest}

The authors declare no conflicts of interest regarding the publication of this paper.

\section{References}

[1] Diouf, M. (2016) Implementation of RNP4 in the EUR/SAM Corridor.

[2] Organisation de l'aviation civile international (OACI) (2013) Performance-Based Navigation (PBN) Manual. ICAO.

[3] Delahaye, D., Alliot, J.M., Schenauer, M. and Farges, J.L. (1995) Genetic Algorithms for Automatic Clustering of Air Traffic Control Sectors. Proceedings of the Conference on Evolutionary Programming, San Diego, March 1995, 8 p.

[4] TranDac, H., Baptiste, P. and Duong, V. (2002) A Constraint Programming Formulation for Dynamic Airspace Sectorization. Proceedings of the 21 st Digital Avionics Systems Conference, Irvine, 27-31 October 2002, 11 p.

[5] Maugis, L., Gotteland, J.-B., Zanni, R. and Kerlirzin, P. (1998) TOSCA-II-WP3: Assessment of the TMA to TMA Handover Concept. Technical Report TOSCA/SOF/WPR/3/03, SOFREAVIA.

[6] Mehadhebi, K. (2000) A Methodology for the Design of a Route Network. Proceedings of the Third Air Traffic Management R D Seminar ATM-2000, Napoli, June 2000, $97 \mathrm{p}$.

[7] Institut National Polytechnique de Toulouse (2006) Optimisation de graphes sous contrainte géométrique: Création d'un réseau de routes aériennes pour un controle Sector-Less.

[8] Letrouit, V. (1998) Optimisation of the European Air Route Network.

[9] ASECNA (2018) Routes superieur de l'espace aerien Dakar. https://ais.asecna.aero

[10] ASECNA (2017) Survey on the Availability of PBN Equipment for Aircraft Using Dakar Airspace. Key PBN Concept (Performance Based Navigation). Bureau Procedures de vol May 2017 ASECNA. 
[11] Thervé, A. (2017) Bureau procédures de vols.

[12] Montcouquiol, G. (2017) Théorie des graphes 2006-2007 (IUT Orsay).

[13] d'après Ahuja, R.K., Magnanti, T.L., Orlin, J.B. and Hall, P. (1993) et d'après les notes des cours de L.A. Wolsey et F. Vanderbeck.

[14] Agency for Aerial Navigation Safety in Africa and Madagascar (ASECNA) (2017) Technical Department of ASECNA (Agency for Aerial Navigation Safety in Africa and Madagascar). 


\section{Annexes}

- This graph represents the determination of the optimal route.

- The optimal route is shown in red.

Road: UG853

After solving Dijkstra and simulating with python language, we found that the shortest distance is $\mathbf{2 6 8 2}$ with the path in red colour, see Figure A1. As a result: ASECNA route is not optimal.

Road: UR975

After solving Dijkstra and simulating with python language, we found that the shortest distance is $\mathbf{1 7 1 0}$ with the path in red colour, Figure A2. As a result: ASECNA route is not optimal.

\section{Road: U615}

After solving Dijkstra and simulating with python language, we found that the shortest distance is 1404, Figure A3. As a result: ASECNA route is optimal.

Algorithm Dijkstra programming in the Python language, see Figure A4. Figure A5 shows following the algorithm Dijkstra programming in the Python language.

Screenshot: Dijkstra solving and simulation with python using real data from the sub-problem (Nouadhibou-Abidjan), see Figures A6-A8.

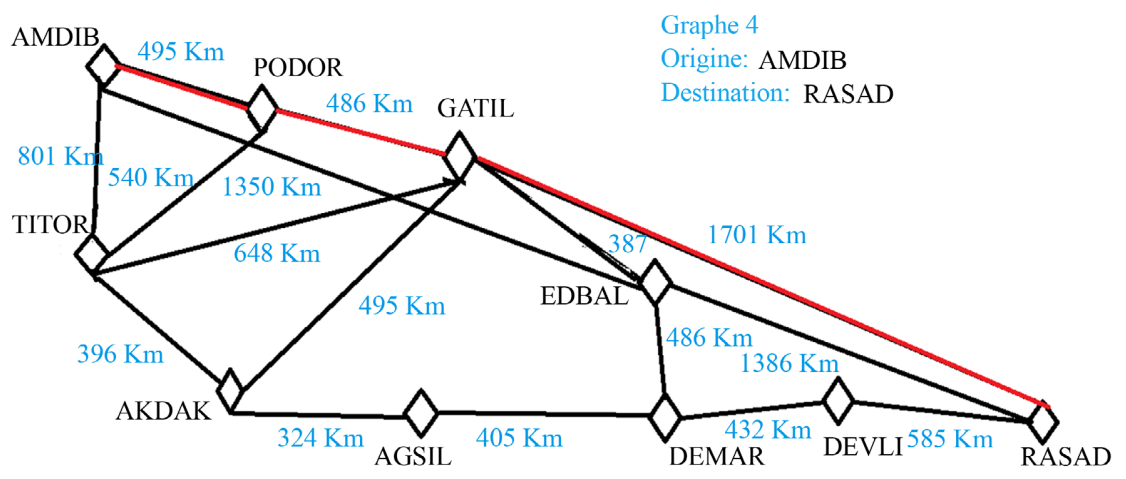

Figure A1. The determination of the UG853 route.

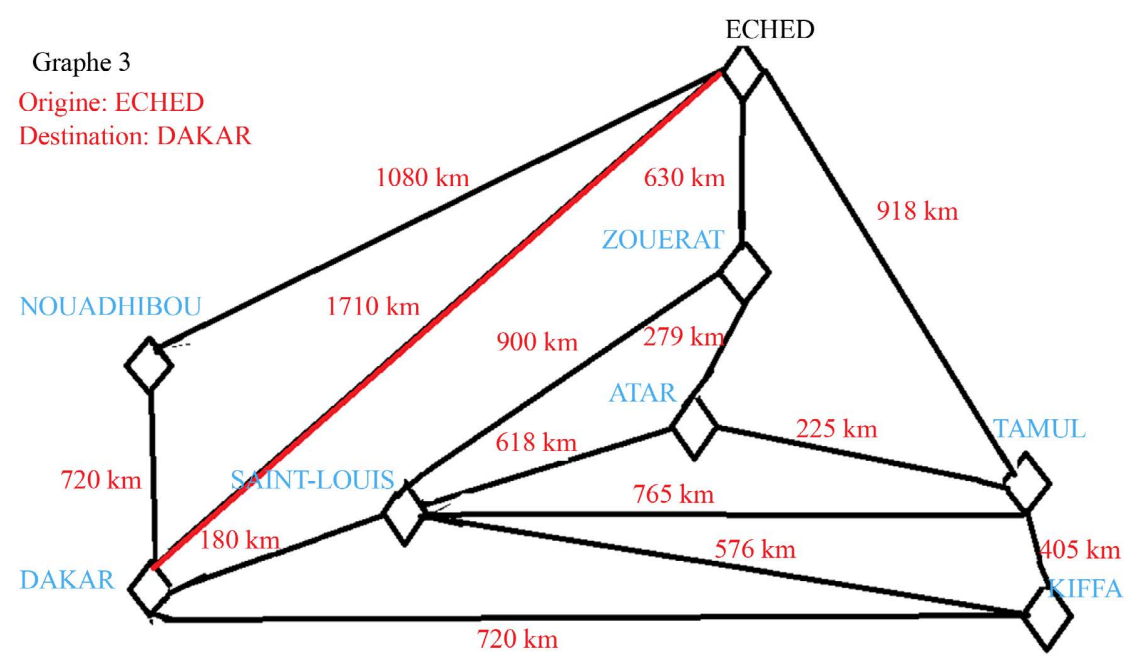

Figure A2. The determination of the UR975 route. 
Graphe 2

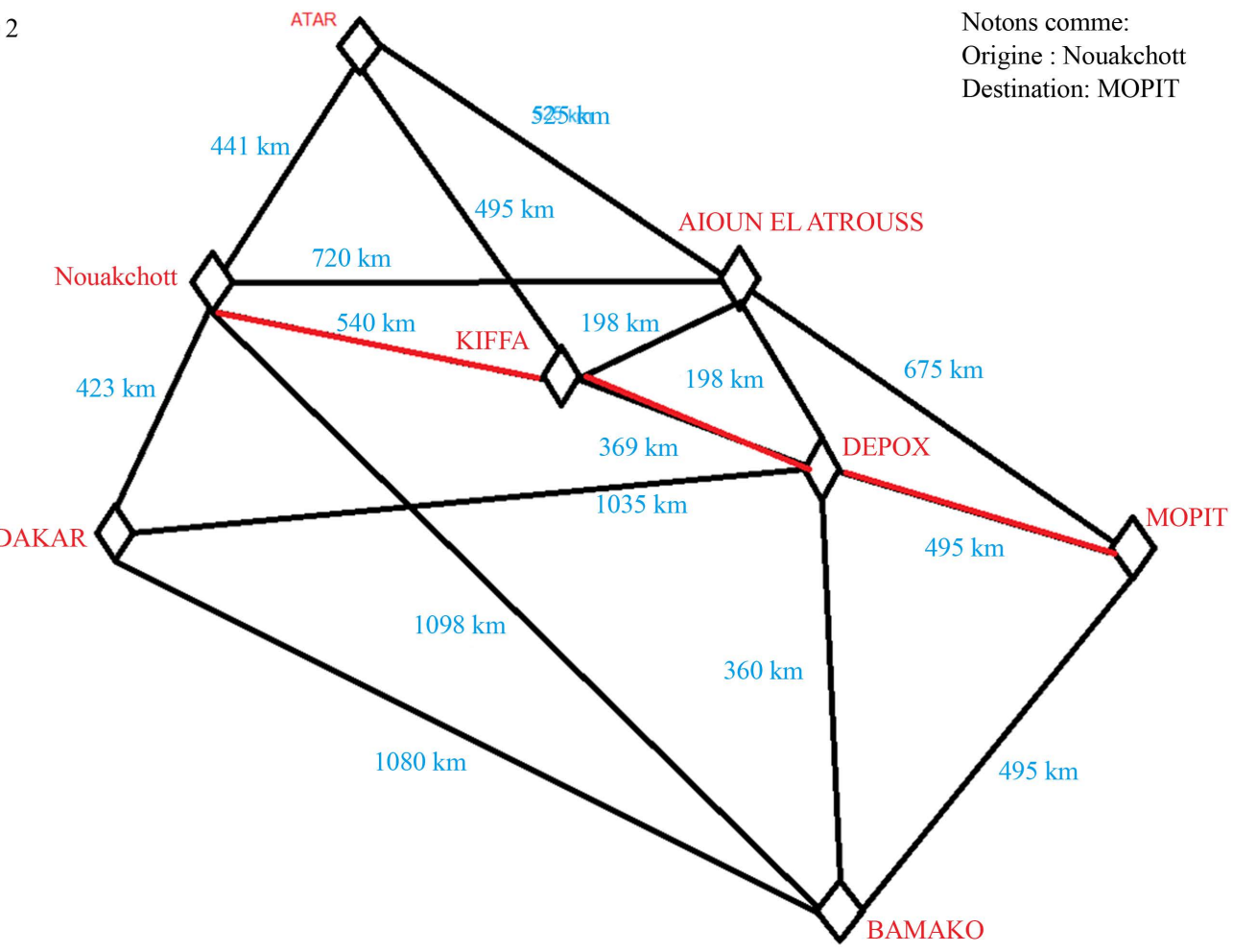

Figure A3. The determination of the U615 route.

code4.py - C:\Users\User \Documents\code4.py (3.6.3)

$-\square \times$

File Edit Format Run Options Window Help

Erom collections import defaultdict

zlass Graph:

def init_(self):

self.nodes $=\operatorname{set}()$

self.edges $=$ defaultdict (list)

self.distances $=\{\}$

def add_node (self, value):

sel $\bar{f}$. nodes.add (value)

def add_edge (self, from_node, to node, distance):

self.

self.edges [to_node] . append (from_node)

self.distances $[$ (from_node, to_node)] = distance

lef dijsktra(graph, initial):

visited $=\{$ initial: 0$\}$

path $=\{\}$

nodes $=$ set $($ graph. nodes $)$

while nodes:

min node $=$ None

for node in nodes:

if node in visited:

if min_node is None:

$\min$ node $=$ node

elif visited[node] < visited[min_node] :

min_node $=$ node

Figure A4. Dijkstra's algorithm. 


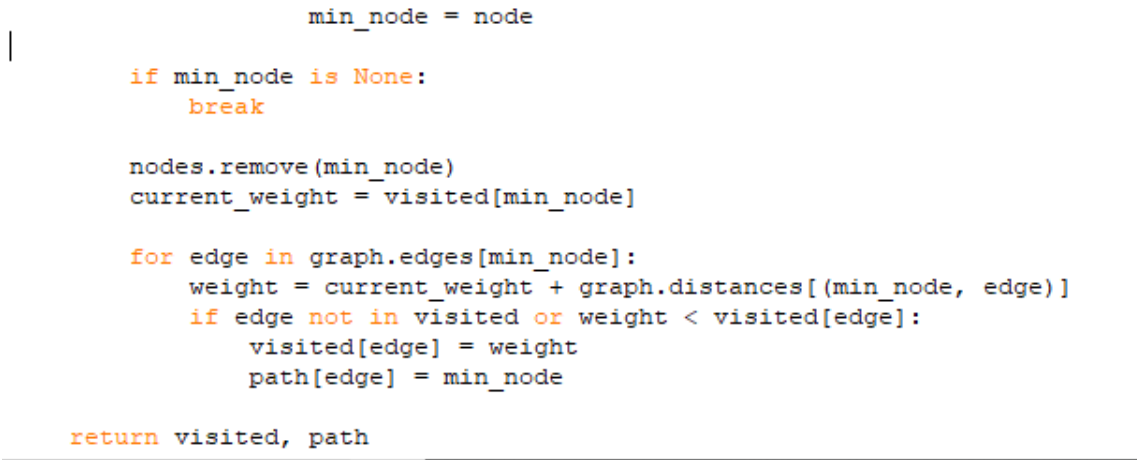

Figure A5. Dijkstra's algorithm.

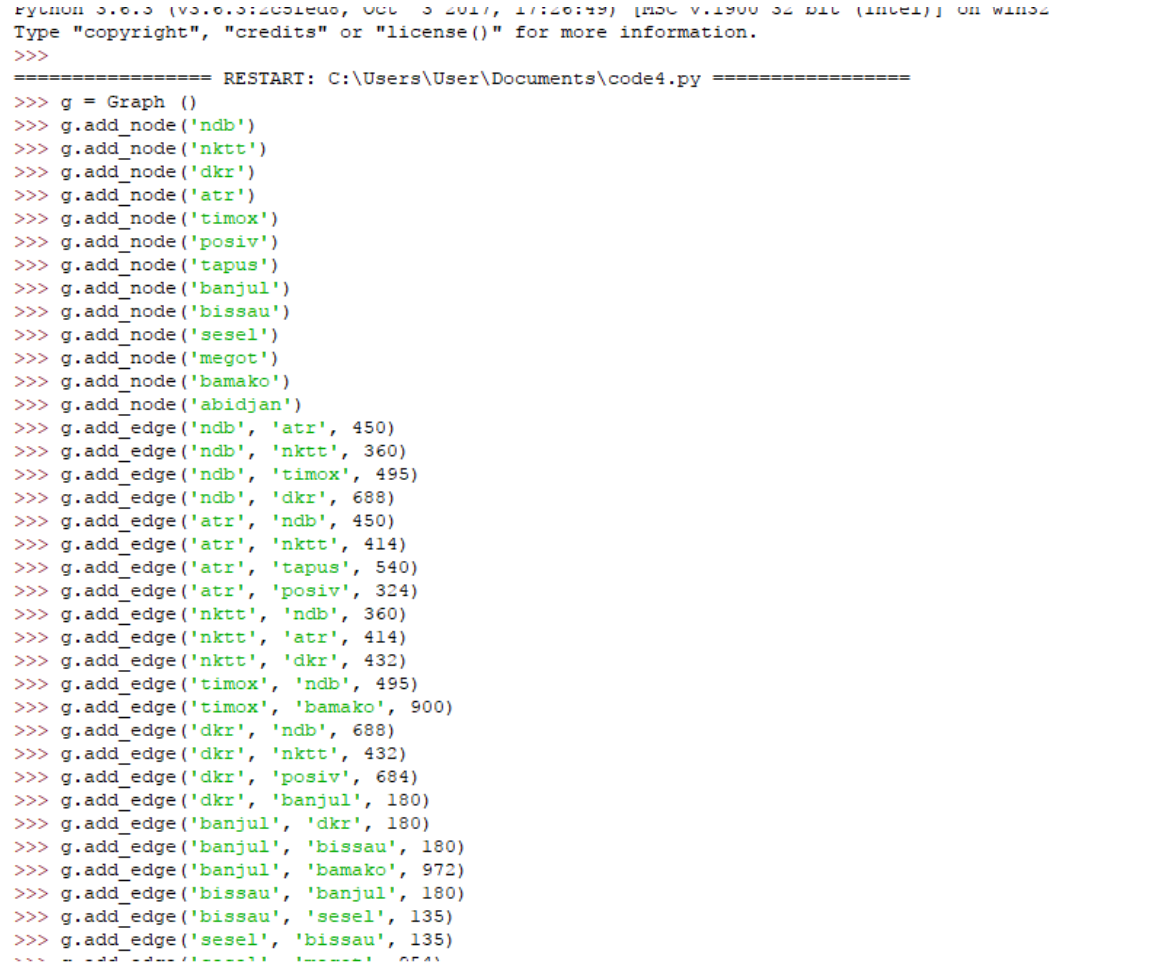

Figure A6. Road: UB600.

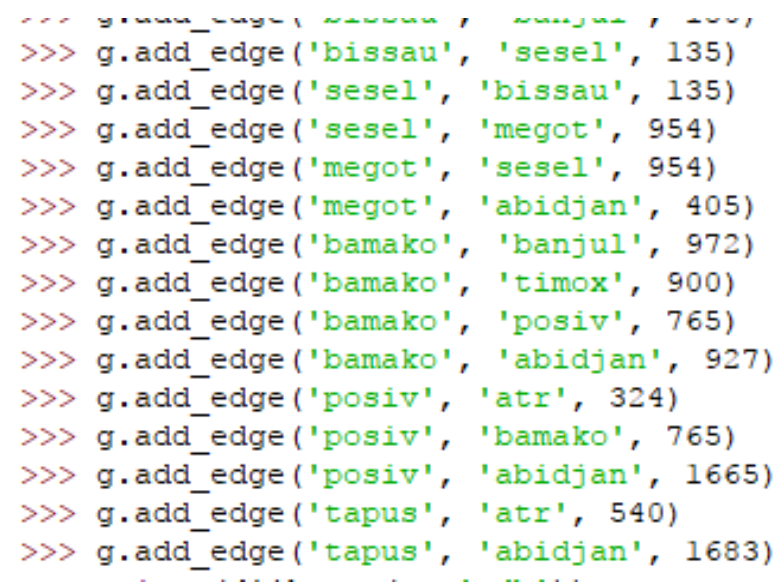

Figure A7. Road: UB600. 


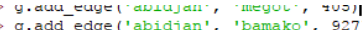

G.add edge ( abidjan', 'bamako', 927)

g.add_edge ('abidjan', 'tapus', 1683)

$>$ print (dijsktra (g, 'ndb'))

. 360, 't timox': 495

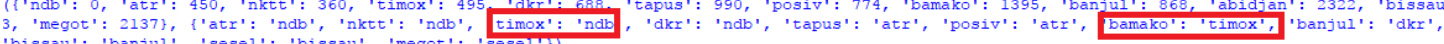

Figure A8. Road: UB600.

\section{List of Acronyms and Abbreviations}

Abbreviations

- ND: NOUADHIBOU

- AT: ATAR

- TM: TIMOX

- NK: NOUAKCHOTT

- DK: DAKAR

- BN: BANJUL

- BI: BISSAU

- SE: SESEL

- MG: MEGOT

- PO: POSIV

- TA: TAPIS

- BM: BAMAKO

- AB: ABIDJAN

List of Acronyms

- Fir: flight information region

- GANP: global air navigation plan

- GPS: global positioning system

- GLONASS: global navigation satellite système

- IVAO: international virtual aviation organization

- NAVID: navigation aids

- ICAO: international civil aviation organization

- RNAV: area navigation

- PBN: performance based navigation 